\title{
Diagnostic value of anti-neuronal antibodies for paraneoplastic disorders of the nervous system
}

\author{
J W B Moll, S C Henzen-Logmans, T A W Splinter, M E L van der Burg, Ch J Vecht
}

\begin{abstract}
The diagnostic value of the presence of anti-neuronal antibodies in serum was examined in 21 patients suspected of paraneoplastic disorders of the nervous system (NS) (group 1) and was compared to three control groups; group 2: 25 patients with a neurological disease, without cancer and no signs of paraneoplastic disorder; group 3: 27 patients with neurological disease and cancer and no signs of a paraneoplastic disorder; group 4: 94 patients with cancer and without neurological disease. In group 1, anti-neuronal nuclear antibodies were detected in eight patients $(38 \%)$, in titres from 1:1000 to 1:32 000. A small cell lung cancer was present in six patients, ovarian cancer in one patient and in one patient no tumour could be detected. The neurological symptoms preceded a diagnosis of cancer in five out of eight patients. Anti-neuronal antibodies were found in the serum of two out of 94 patients $(2 \%)$ from control group 3 but not in serum from any of the other control groups. These data indicate a moderate sensitivity of $38 \%$, but a high specificity of $98.6 \% \quad(95 \%$ confidence interval $95 \cdot 5-99 \cdot 8 \%$ ) for the presence of anti-neuronal nuclear antibodies if a paraneoplastic NS disorder is suspected.
\end{abstract}

Cancer Center,

Rotterdam

Department of

Neurology

J W B Moll*

Ch J Vecht

Department of Pathology*

$S$ C Henzen-Logmans

Department of

Medical Oncology

$M E L$ van der Burg

University Hospital

Dijkzigt, Rotterdam,

The Netherlands

Department of

Neurology

Ch J Vecht

Department of

Medical Oncology

T A W Splinter

Correspondence to:

Dr Vecht, Department of

Neurology, Dr Daniel den

Hoed Cancer Center, 3075

EA Rotterdam, The

Netherlands.

Received 8 December 1989

and in revised form

2 April 1990.

Accepted 10 April 1990

Paraneoplastic disorders of the nervous system (NS) can be divided mainly into limbic encephalitis, brainstem encephalitis, subacute cerebellar degeneration and a sensory or motor neuronopathy. In more than $50 \%$ of cases, they precede the finding of the underlying neoplasm. ${ }^{1}$ Diagnosis during life can be difficult because clinical symptoms and findings on ancillary investigations are not specific. In recent years, several anti-neuronal auto-antibodies have been identified in the serum of patients with a paraneoplastic disorder of the NS. ${ }^{2-4}$ The antinuclear nucleoprotein antibody (anti-Hu) is mainly associated with small cell lung carcinoma (SCLC) and binds to nuclei of neurons. ${ }^{25}$ The anti-Purkinje cell antibody (APCA) binds to the cytoplasm of Purkinje cells and has primarily been identified in patients with breast and ovarian cancer. ${ }^{36}$ Apart from its interest in the aetiology of paraneoplastic NS syndromes, the finding of these autoantibodies can be used for diagnostic pur- poses. We investigated the diagnostic value of the presence of anti-neuronal antibodies in patients with neurological signs suspected of paraneoplastic origin and compared it with three control groups.

\section{Patients and methods}

Indirect immunofluorescence technique

The presence of anti-neuronal auto-antibodies was investigated by the indirect immunofluorescence method (IIF). Snap frozen tissue blocks of human neuronal tissue (obtained at necropsy within six hours after death, from individuals without neurological disease) and with fresh neuronal tissue obtained from healthy Wistar rats, were used as test tissue. Unfixed frozen sections of human and rat cortex, cerebellum, spinal cord and vagal and optic nerve were incubated with serum diluted with phosphate-buffered saline (PBS, $\mathrm{pH} \mathrm{7.2)} 1: 50$ up to $1: 6400$, for one hour at room temperature. After rinsing three times in PBS for five minutes the sections were incubated with anti-human Ig and IgG (Fab)2, IgM (Fab)2 and IgA (Fab)2 monoclonal antibodies conjugated with fluorescein isothiocyanate (FITC) for 30 minutes (Dako, Denmark). The dilution for the second antibody was 1:100 for $\operatorname{Ig}, \operatorname{IgG}(\mathrm{Fab}) 2$ and 1:50 for IgM (Fab)2. Sections were rinsed three times in PBS for five minutes, overlaid with a coverglass using a $10 \%$ glycine/PBS solution as mounting fluid, and evaluated under a Leitz fluorescence microscope with a FITC outfit.

As negative controls, sections were also incubated with PBS alone. To differentiate anti-neuronal antibodies from non-neuronal specific anti-nuclear antibodies, sera were also tested against frozen sections of normal human and rat liver. Stained sections were reviewed by the investigator and technician without previous knowledge of the patient's clinical status. Sera were considered positive for anti-neuronal antibodies only when distinct fluorescence staining was present in a titre of 1:500 or higher. Antibody-positive sera were also incubated with frozen sections of normal human and rat cerebral cortex, cerebellum, spinal cord, optical and vagal nerve.

Four different categories of patients were distinguished: Group 1: patients with or without a verified cancer, in whom a reasonable or strong suspicion of a paraneoplastic NS disorder was present. Three case reports from this group have been described in detail ${ }^{7}$; Group 2: control group of 25 patients with 
neurological disease not related to a paraneoplastic NS disorder and without cancer; Group 3: control group of 27 patients with neurological disease not related to a paraneoplastic NS disorder and with cancer; Group 4: control group of 94 patients with cancer and no known neurological disease. Control sera of group 4 were collected over a period of five years and stored at $-70^{\circ} \mathrm{C}$. All patients in this group were prospectively studied and followed as part of ongoing chemotherapy trials.

All sera of groups 1, 2, 3 and 4 were negative for anti-nuclear antibodies (ANF), when tested on normal human and rat liver or muscle tissue. In peripheral nerve or nonneuronal tissue, no reactivity could be observed using the same sera. No differences were seen in staining patterns on human or rat tissue.

\section{Results}

The number of patients in each group and a listing of the neurological diagnoses are summarised in table 1 . The individual clinical and IIF data in patients with positive titres can be found in table 2 . Anti-neuronal antibodies were detected in eight out of 21 patients from group $1(38 \%)$ : in six patients with SCLC, in one patient with ovarian carcinoma and in one patient no tumour could be found. A bright speckled fluorescence of nuclei of cerebellar granular and Purkinje cells and cortical neurons with sparing of the nucleolus was observed in six patients (fig 1 and 2). This antineuronal nuclear antibody was of the IgG type (titres from 1:1000 to $1: 32000$ ), except one

\section{Table 1}

\begin{tabular}{|c|c|c|c|}
\hline \multicolumn{4}{|c|}{ Groups of patients } \\
\hline \multirow[t]{2}{*}{1} & \multicolumn{2}{|c|}{$\begin{array}{l}\text { Neurological disease with suspicion of } \\
\text { paraneoplastic NS disease }\end{array}$} & $\overline{21}$ \\
\hline & $\begin{array}{l}\text { organic brain syndrome } \\
\text { cerebellar ataxia } \\
\text { sensory neuronopathy } \\
\text { myelopathy } \\
\text { brainstem encephalitis }\end{array}$ & $\begin{array}{l}5 \\
6 \\
5 \\
4 \\
1\end{array}$ & \\
\hline 2 & \multicolumn{2}{|c|}{$\begin{array}{l}\text { Neurological disease without cancer and no } \\
\text { suspicion of paraneoplastic NS disease }\end{array}$} & 25 \\
\hline 3 & \multicolumn{2}{|c|}{$\begin{array}{l}\text { Cancer with neurological disease but no } \\
\text { suspicion of paraneoplastic NS disease }\end{array}$} & 27 \\
\hline 4 & \multicolumn{2}{|c|}{ Cancer without neurological disease } & 94 \\
\hline & $\begin{array}{l}\text { small cell lung cancer } \\
\text { breast cancer } \\
\text { ovarian cancer }\end{array}$ & $\begin{array}{r}38 \\
9 \\
47\end{array}$ & \\
\hline
\end{tabular}

patient with an IgM antibody (titre 1:1000). Neurological symptoms preceded the diagnosis of a neoplasm in five out of the eight positive patients from group 1 with a median time interval of four months. An organic brain syndrome, compatible with a diagnosis of limbic encephalitis was seen in three patients with SCLC.

Extensive investigations including CT scan of the brain, bacterial and viral cultures of the cerebrospinal fluid (CSF) were negative. Causes for metabolic encephalopathies could be excluded and there were no indications of toxic exposure or drug abuse. Psychiatric evaluation did not reveal a cause for the mental abnormalities. A subacute cerebellar degeneration consisting of a truncal and appendicular ataxia together with dysarthria was seen in two patients with SCLC. A sensory neuronopathy in association with abnormal plantar reflexes was found in one patient with SCLC and in one patient in whom no tumour could be detected. A brain stem encephalitis consisting of a peripheral facial palsy, vestibular vertigo, glossopharyngeal and vagal nerve dysfunction, dysarthria and pyramidal signs, was observed in a patient with ovarian carcinoma.

In the controls, only two patients of group 3 had increased titres of anti-neuronal nuclear antibodies, and both had a SCLC. One of these had recurrent headache with equivocal signs of a pyramidal tract lesion, but no other neurological signs. The other patient had brain metastases, treated by radiotherapy and was neurologically asymptomatic at the time serum was taken. When we consider group 2, 3 and 4 as one control group, the presence of antineuronal nuclear antibodies in patients suspected of a paraneoplastic NS disorder (group 1) indicate a sensitivity of $38 \%$ and a specificity of $98.6 \%$ (95\% confidence interval $95 \cdot 5-99 \cdot 8 \%$ ) see table 3 .

\section{Discussion}

Anti-neuronal IgG antibodies in serum of patients with a paraneoplastic disorder of the NS have been identified, and can mainly be divided in anti-neuronal nuclear or cytoplasmic antibodies. ${ }^{24}$

Antibodies binding to neuronal nuclei have been observed in Purkinje, granular, basket and molecular cells of the cerebellum as well as

Table 2 Clinical and IIF data of patients with anti-neuronal nuclear antibodies

\begin{tabular}{|c|c|c|c|c|c|c|c|c|c|c|c|c|}
\hline & \multirow[b]{2}{*}{ Tumour } & \multirow{2}{*}{$\begin{array}{l}\text { Onset } \\
\text { (months) }\end{array}$} & \multirow[b]{2}{*}{ Main clinical feature } & \multirow[b]{2}{*}{ Titre } & \multirow[b]{2}{*}{ Class } & \multicolumn{7}{|c|}{ Antibody specificity } \\
\hline & & & & & & $C N$ & $P C$ & $G C$ & $B C$ & $s C$ & $M L C$ & $A H C$ \\
\hline \multicolumn{13}{|c|}{ Group 1} \\
\hline 1 & SCLC & -0.5 & Organic brain syndrome & $1: 1600$ & IgG & + & - & + & - & - & - & - \\
\hline 2 & SCLC & $-2 \cdot 5$ & Organic brain syndrome, seizures & $1: 1000$ & IgM & + & + & + & + & + & + & - \\
\hline 3 & SCLC & -24 & Ataxia, dysarthria & $1: 4000$ & IgG & + & + & + & + & + & + & - \\
\hline 4 & SCLC & -2 & Ataxia, dysarthria, sensory neuronopathy & $1: 32000$ & IgG & - & + & + & - & - & - & - \\
\hline 5 & SCLC & +4 & Organic brain syndrome & $1: 2000$ & IgG & - & + & + & + & + & - & - \\
\hline 6 & Ovarian cancer & +9 & Brain stem encephalitis & $1: 6400$ & IgG & + & + & + & + & + & + & - \\
\hline 7 & No tumour & & Sensory neuronopathy & $1: 1600$ & IgG & & & & & & & \\
\hline 8 & SCLC & -6 & Sensory neuronopathy & $1: 25000$ & IgG & - & + & + & - & - & - & - \\
\hline \multicolumn{13}{|c|}{ Group 3} \\
\hline 9 & SCLC & & Brain metastasis & $1: 800$ & IgG & - & + & + & - & - & - & - \\
\hline 10 & SCLC & & Pyrimidal tract lesion & $1: 6400$ & IgG & - & + & + & + & + & + & - \\
\hline
\end{tabular}

Onset: time of onset of symptoms before detection of tumour, SCLC: small cell lung cancer, CN: Cerebral cortical neuron, PC: Purkinje cell, GC: Granular cell, BC: Basket cell, SC: Stellate cell, MLC: Molecular layer cell, AHC: Anterior horn cell 


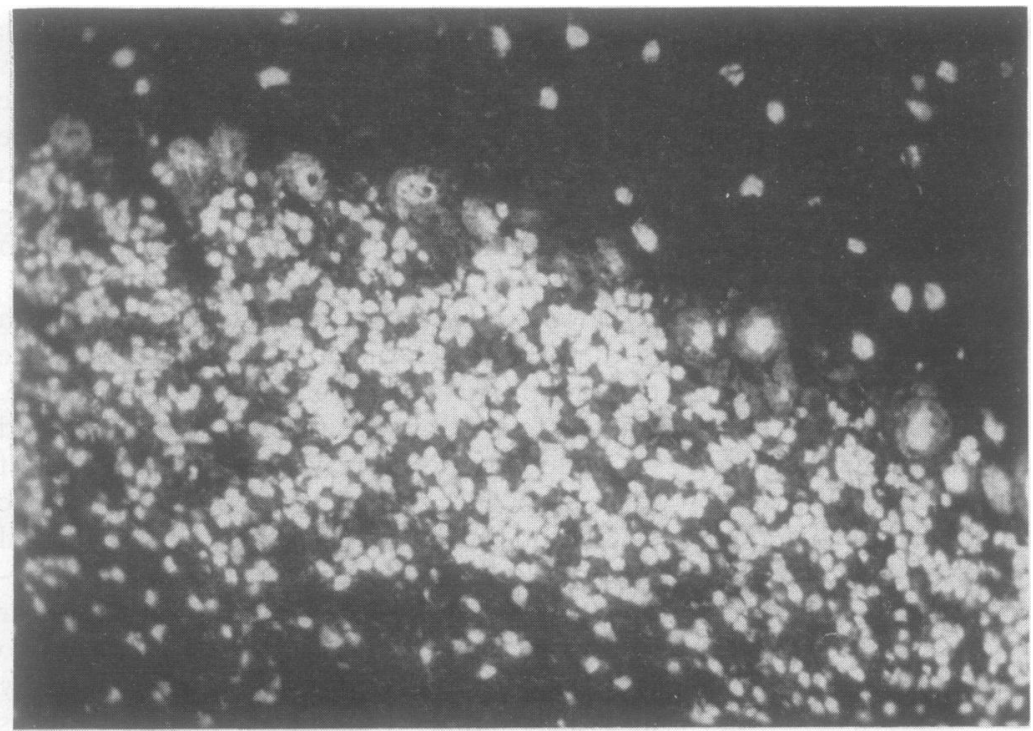

Figure 1 Indirect immunofluorescence (dilution 1:100) of nuclei of granular and Purkinje cells with sparing of nucleoli $(200 \times)$.

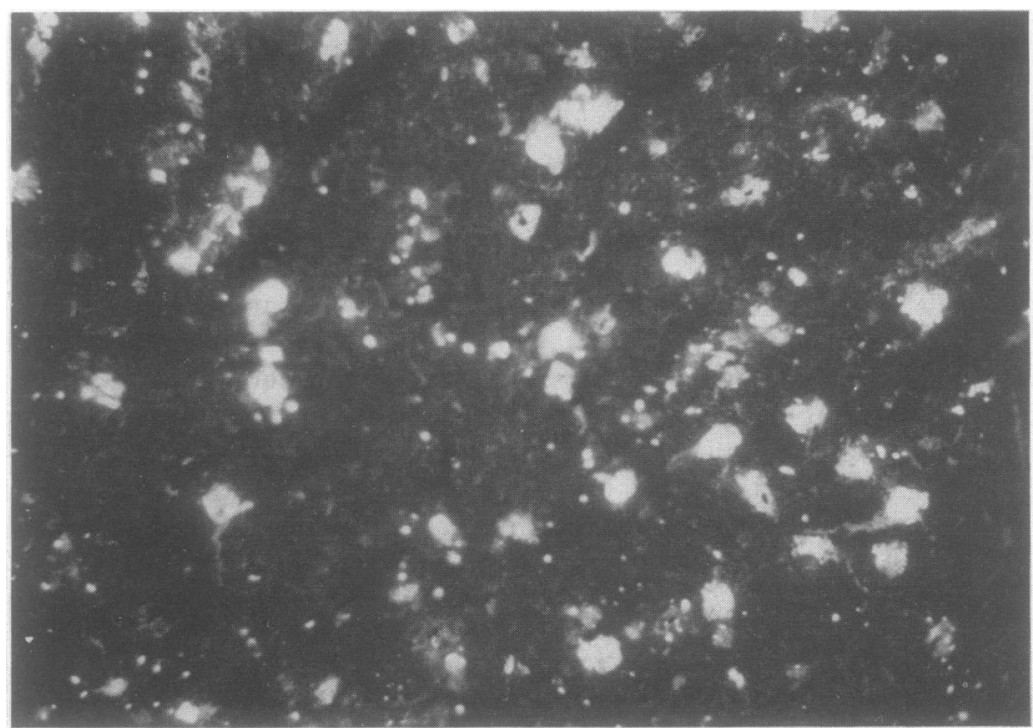

Figure 2 Indirect immunofluorescence (dilution 1:100) of nuclei of cells in cerebral cortex with sparing of nucleoli $(400 \times)$.

to nuclei of neurons in the cerebral cortex, brainstem, spinal cord and dorsal root ganglion. ${ }^{25}$ These anti-neuronal nuclear antibodies have primarily been recognised as binding to neuronal nucleoprotein antigens with a molecular weight of 35-40 $\mathrm{Kd}$ and have been designated as anti-Hu. ${ }^{25}$ The majority of anti-Hu antibodies are associated with SCLC. ${ }^{2-5}$ We found anti-neuronal nuclear antibodies in three patients with an organic brain syndrome and these were compatible with a diagnosis of limbic encephalitis, in two patients with cerebellar ataxia and in one patient with a sensory neuronopathy, all with SCLC. An isolated IgM antibody in a patient with SCLC and suspected of limbic encephalitis is a new observation. An anti-neuronal nuclear antibody in a patient with brain stem encephalitis and ovarian cancer has also not been reported before. The cause of this variation in clinical syndromes is unknown, but it may relate to differences in anti-nuclear antibodies or variability in binding to one group of neurons or another.

In contrast, anti-neuronal cytoplasmic antibodies have primarily been associated with binding to Purkinje cells together with the occurrence of cerebellar ataxia and have been designated as APCA (anti-Purkinje cell antibodies). ${ }^{346}$ The clinical picture is usually designated as a paraneoplastic subacute cerebellar degeneration and has been encountered in gynaecological cancer, mainly ovarian, in breast and small cell lung cancer or in lymphoma. ${ }^{346}$ In more than $50 \%$ of cases the paraneoplastic neurological disorder precedes the finding of a malignancy, ${ }^{1}$ which we also observed here. Until recently a final diagnosis of paraneoplastic disorder of the NS could only be confirmed at necropsy since the results of ancillary investigations are often negative or aspecific. Viral and post-viral inflammatory disease, Sjögren's syndrome or an idiopathic syndrome may give rise to similar clinical pictures. ${ }^{89}$ The detection therefore of antineuronal auto-antibodies in serum of patients suspected of a paraneoplastic NS syndrome could be of great help. ${ }^{56}$ For this purpose information is needed about the sensitivity and specificity of the presence of these autoantibodies.

For anti-Hu antibodies, Anderson et al found a specificity of almost $100 \%$ in a series of 18 patients with paraneoplastic NS disorder together with various control groups up to a total of 303 patients with or without cancer or neurological abnormalities. ${ }^{5}$ They found false positive antibodies in two patients with a possible paraneoplastic neurological syndrome, but without the presence of a malignancy. ${ }^{5}$ We found positive auto-antibodies in two control patients of group 3. Two of these had a small cell lung cancer of the lung and positive titres of anti-neuronal nuclear antibodies. Neither of them had signs which are usually compatible with a paraneoplastic disorder of the NS. When we restrict ourselves to patients with positive titres of anti-neuronal

Table 3 Diagnostic value of anti-neuronal antibodies for the presence of a paraneoplastic NS disorder

\begin{tabular}{|c|c|c|c|c|}
\hline & $\begin{array}{l}\text { Number of positive tests } \\
\text { in suspected patients }\end{array}$ & $\begin{array}{l}\text { Number of negative tests } \\
\text { in control patients }\end{array}$ & Sensitivity & Specificity \\
\hline $\begin{array}{l}\text { Anti-neuronal nuclear antibodies } \\
\text { Anderson et al } 1988^{5} \\
\text { This series }\end{array}$ & $\begin{array}{r}s \\
14 / 87 \\
8 / 21\end{array}$ & $\begin{array}{l}303 / 303 \\
144 / 146\end{array}$ & $\begin{array}{l}14 \cdot 5 \% \\
38 \%\end{array}$ & $\begin{array}{r}100 \% \\
98 \%\end{array}$ \\
\hline $\begin{array}{l}\text { Anti-neuronal cytoplasmic antibo } \\
\text { Jaeckle et al }{ }^{4} 1985 \\
\text { Anderson et al } 1988 \\
\text { Smith et al } 1988\end{array}$ & $\begin{array}{r}\text { odies } \\
6 / 12 \\
18 / 42 \\
6 / 26\end{array}$ & $\begin{array}{l}167 / 167 \\
317 / 319 \\
125 / 125\end{array}$ & $\begin{array}{l}50 \% \\
43 \% \\
23 \%\end{array}$ & $\begin{array}{r}100 \% \\
99 \% \\
100 \%\end{array}$ \\
\hline
\end{tabular}

*In this table only series in which a titre of 1:500 or higher was considered to be positive have been included. 
nuclear antibodies in serum, we found a specificity of $98^{\circ}{ }_{0}$ for the association of these antibodies with a suspected paraneoplastic disorder of the NS.

The presence of APCA has also been shown to be highly specific for a diagnosis of a paraneoplastic cerebellar degeneration. ${ }^{610}$ In contrast to its specificity, the diagnostic sensitivity for the presence of either anti-Hu or APCA-antibodies was rather low in the few reported series, but this may be partly due to differences in opinion on a sufficiently high titre in serum. ${ }^{112} \mathrm{~A}$ cut-off point of a titre of 1:500 or higher prevents a false-positive interpretation of non-specific background stain. ${ }^{5610}$ Despite this precaution, the sensitivity may further differ from one series to another as the degree of clinical suspicion and the interpretation of subtle neurological findings is open to variation. Nevertheless, its high specificity makes the indirect immunofluorescence test a clinically useful screening test for the detection of anti-neuronal antibodies in serum of patients suspected of paraneoplastic disorder of the NS.

We thank Drs J Boiten (Department of Neurology, University Hospital Maastricht), P A van Doorn (Department of Neurology, University Hospital Rotterdam), A $M$ van Hulst (Department of Psychiatry, University Hospital Rotterdam), R $A$ van der Kruyk and A $R$ Wattendorff (Department of Neurology, Leyenburg Hospital, The Hague) for allowing us to use the clinical data of patients under their care. We are grateful to Corine Kort for her assistance in preparing the manuscript.

1 Henson RA, Urich H. Cancer and the nervous system: the neurological manifestations of systemic disease. Oxford: neurological manifes

2 Graus F, Elkon KB, Cordon-Cardo C, Posner JB. Sensory neuronopathy and small cell lung cancer. Antineuronal antibody that also reacts with the tumor. Am J Med 1986; 80:45-52.

3 Greenlee JE, Brashear HR. Antibodies to cerebellar Purkinje cells in patients with paraneoplastic cerebellar degeneration and ovarian carcinoma. Ann Neurol 1983; 14:609-13.

4 Jaeckle KA, Graus F, Houghton A, et al. Autoimmune response of patients with paraneoplastic cerebellar degeneration to a Purkinje cell cytoplasmic protein antigen. Ann Neurol 1985;18:592-600.

5 Anderson NE, Rosenblum MK, Graus F, Wiley RG, Posner JB. Auto-antibodies in paraneoplastic syndromes with JB. Auto-antibodies in paraneoplastic syndromes
small cell lung cancer. Neurology 1988;38:1391-8.

6 Anderson NE, Rosenblum MK, Posner JB. Paraneoplastic cerebellar degeneration: clinical immunological correlations. Ann Neurol 1988;24:559-67.

7 Moll JWB, Henzen-Logmans SC, Vecht ChJ. Antineuronal antibodies in paraneoplastic neurological disorders of the central nervous system with small cell lung carcinoma. Clin Neurol Neurosurg 1990;92:223-8.

8 Malinow K, Yannakakis GD, Glusman SM, et al. Subacute sensory neuronopathy secondary to dorsal root ganglionitis in primary Sjögren's syndrome. Ann Neurol 1986;20:535-7.

9 Daniel SE, Love S, Sravilli F, Harding AE. Encephalomyeloneuropathy in the absence of a detectable neoplasm myeloneuropathy in the absence of

10 Smith JL, Finley JC, Lennon VA. Auto-antibodies in paraneoplastic cerebellar degeneration bind to cytoplasmic antigens of Purkinje cells in humans, rats and mice and are of multiple immunoglobulin classes. $J$ Neurolimmunol 1988;18:37-48.

11 Popp W, Drlicek M, Grisold W, Zwick H. Circulating antineuronal antibodies in small cell lung cancer. Lung 1988;166:243-51.

12 Grisold W, Drlicek M, Popp W, Jellinger K. Antineuronal antibodies in small cell lung carcinoma-a significance for paraneoplastic syndromes. Acta Neuropathol 1987;75: 199-202. 